\title{
High Glycosylated Haemoglobin Increased Prevalence of Proliferative Diabetic Retinopathy
}

\author{
Ni Made Ari Suryathi, I Putu Budhiastra, I W.G.Jayanegara
}

\begin{abstract}
Diabetic retinopathy (DR) is one of the microvascular complication in diabetes mellitus (DM). Glycosylated hemoglobin (HbA1c) is an indicator that reflects the percentage of blood glucose tied to hemoglobin for the past three months. This study aims to determine if a high level of HbA1c increases the prevalence of proliferative diabetic retinopathy. Cross-sectional study. The participants were DM patients who were diagnosed with PDR and NPDR for the first time and HbA1c level was checked in the laboratory. Of the 74 participants, 37 participants were PDR, and 37 participants were NPDR. The ratio of prevalence (PR) was 3.87 , with Confident of Interval (CI 95\%): 1.96-7.67 and $p<0.001$. Multivariate analysis shows Odd Ratio (OR) of HbA1c is 18.319 (5.334-62.919) and $p<0.001$. High level of HbA1c as a risk factor of high prevalence of PDR.
\end{abstract}

Index Terms - Diabetic retinopathy, diabetes mellitus, glycosylated hemoglobin

\section{INTRODUCTION}

$\mathrm{DR}$ is a retinal disorder due to microvascular complications of DM. DR is the most common cause of blindness after cataracts. The number of DM patients worldwide is estimated more than 360 million people and expected to increase more than two times by 2030 [1]. The purpose of this study was to find out the glucoregulation of patients with PDR and NPDR, expressed by levels of HbAlc and the specific aim of this study was to determine whether a high level of HbAlc increases the prevalence of proliferative diabetic retinopathy.

\section{METHODS}

\section{A. Study Design}

A cross-sectional study was conducted to examine whether the high levels of HbAlc lead to increased prevalence of PDR patients with DR at the Internal Medicine clinic in the Endocrine Division of Sanglah Hospital, Eye clinic at Sanglah Hospital and Indra Hospital. The study was conducted from October 3, 2014 to January 31, 2015. The inclusion criteria were DM patients who willing to take part in the study and sign informed consent. The exclusion criteria were patients with intraocular infection or inflammation, subjects with abnormalities in anterior and posterior eye's chamber which can interfere visualization during retinal examination other than RD, subjects with anemia, chronic kidney failure, thalassemia, subjects who consumed high doses of vitamin $\mathrm{C}$ and $\mathrm{E}$ for the last one month, and subjects with obesity.

\section{B. Sample Recruitment}

The samples were selected by a consecutive sampling technique from registered patients. The chosen sample was patients with DM who had either NPDR or PDR in one or both eyes, but if both eyes had different retinopathy degree than the patients were included in the diabetic retinopathy group with a higher stadium (PDR).

The collection of the data was carried out through interviews, physical examination, ophthalmologic examination, and blood sampling. The diagnosis of NPDR and PDR was recorded in an ophthalmological state examination sheet and research questionnaire sheet. Patients with diabetic retinopathy were then determined to have NPDR or PDR and then blood samples and HbA1c levels were tested.

The stages of data analysis include data selection, namely editing, coding and tabulation inserted to file navigator of Statistical Package for The Social Sciences (SPSS) program. Descriptive statistical analysis, the calculation of diabetic retinopathy prevalence, NPDR prevalence, and PDR prevalence, the cutoff point of HbA1c levels was known by using the ROC curve. AUC value is considered well if $\geq$ $70 \%$. The calculation of the ratio of prevalence (PR) of PDR compared to diabetic retinopathy using a $2 \times 2$ table. Logistic regression multivariate analytic was used to look at the risk factor, odds ratio (OR) from the variable age, sex, and the duration of DM to PDR with CI 95\% and statistically significant if $\mathrm{p}<0.05$.

\section{RESULTS}

A total of $123 \mathrm{DM}$ patients, divided into $74 \mathrm{DM}$ patients with DR and 49 DM patients without DR were evaluated. Seventy four DM patients with DR were divided into two groups, the PDR group and NPDR group, and each group consisted of 37 participants. These two groups underwent laboratory HbAlc testing. Table 1 shows the mean HbAlc level in the PDR group was $9.40 \pm 2.17 \%$. The mean HbA1c level in NPDR group was $7.06 \pm 1.97 \%$. This study shows that the prevalence of DR in DM patients was $60.16 \%$. This study also shows that among patients with DR, the prevalence of PDR and NPDR in DR was $30.08 \%$ each group (Table I).

TABLE I: RESEARCH SUBJECT CHARACTERISTIC

\begin{tabular}{lcc}
\hline \multicolumn{1}{c}{ Characteristic } & PDR & NPDR \\
\hline Age (year) $\{$ Mean \pm SD $\}$ & $56.00 \pm$ & $57.32 \pm$ \\
& 7.60 & 9.74 \\
Sex $\{\mathrm{n}(\%)\}$ & & \\
Male/Men & $19(51 \%)$ & $20(54 \%)$ \\
Female/Women & $18(49 \%)$ & $17(46 \%)$ \\
Duration of diagnosed by DM (year) & $9.72 \pm 3.92$ & $8.50 \pm 2.92$ \\
$\{$ Mean \pm SD $\}$ & & \\
High HbA1c $\left\{\mathrm{n} / \sum \mathrm{n}(\%)\right\}$ & $31 / 37$ & $9 / 37$ \\
& $(83.8 \%)$ & $(24.3 \%)$ \\
Normal HbA1c $\left\{\mathrm{n} / \sum \mathrm{n}(\%)\right\}$ & $6 / 37$ & $28 / 37$ \\
& $(16.2 \%)$ & $(75.7 \%)$ \\
\hline \hline
\end{tabular}

Receiver Operating Characteristic (ROC) curve is used to see the AUC (Area Under Curve) and to determine the cut off point of HbAlc. Figure 1 shows the ROC (Receiver Operating Characteristic) curve and AUC (Area Under 
Curve) value. The AUC value was $85.2 \%$, with $95 \%$ CI with a lower limit of $76.1 \%$ and an upper limit of $94.3 \%$ and $p$ $<0.001$ statistically strong because it was greater than the minimum AUC value expected by researchers, which was $70 \%$. The purpose of the diagnostic test in this study is to determine the cut off point. The cut point with a high sensitivity level needs to be found. The cut point of ROC (cut off point) curve has been selected at sensitivity 0.816 so that a high level of HbAlc was obtained and that was more than $7.77 \%$ (Fig. 1).

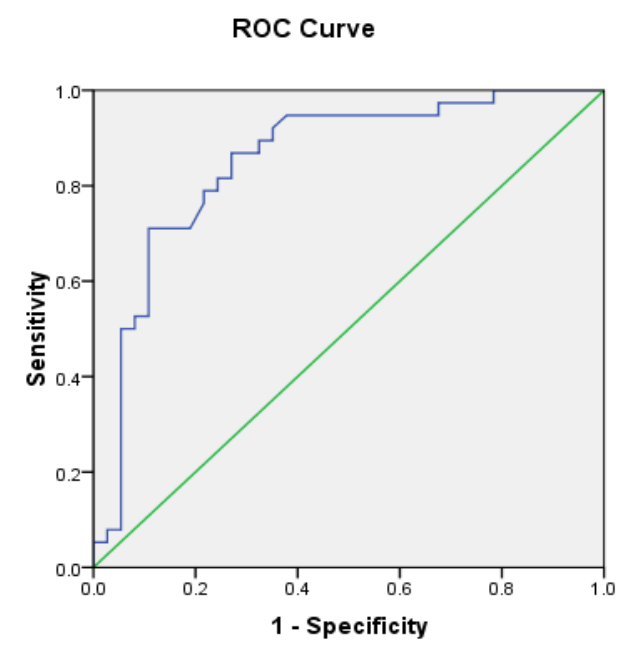

Diagonal segments are produced by ties.

Fig. 1. the ROC (Receiver Operating Characteristic) curve and AUC (Area Under Curve) value.

The logistic regression multivariate analysis between the variables of age, sex, duration of DM, HbAlc levels and PDR. Variables of age, sex, and duration of diagnosed with DM were not significant of the PDR prevalence $(p>0.05)$. A high $\mathrm{HbA1c}$ level $(>7.77 \%)$ increases the risk of $18.33 \%$ of the prevalence of PDR (Odd Ratio = 5.334-62,919). This was statistically significant $(\mathrm{p}<0.001)$ (Table II).

Table II: Logistic Regression Multivariate Analysis's Result

\begin{tabular}{llll}
\hline \hline Variable & Coefficient & $\begin{array}{l}\text { OR } \\
(\text { CI 95\%) }\end{array}$ & $\mathrm{p}$ \\
\hline Age & 0,294 & $\begin{array}{l}1,342 \\
(0,351-5,126)\end{array}$ & 0,667 \\
Sex & 0,137 & $\begin{array}{l}0,872 \\
(0,267-2,842)\end{array}$ & 0,820 \\
& & 1,797 & 0,483 \\
Duration of DM & 0,586 & $(0,349-9,250)$ & \\
& & 18,319 & $<0,001$ \\
HbA1c level & 2,908 & $(5,334-62,919)$ & 0,37 \\
& & 0,130 & \\
Constant & $-2,040$ & & \\
\hline \hline
\end{tabular}

\section{DISCUSSION}

Important risk factor for diabetic retinopathy to occur in people with DM is age. Several studies have reported that the prevalence of DR has increased with the increasing of age [2]. Ageing can reduce body function which is caused by the cell apoptosis which begins at the age of more than 45 years old. The condition of chronic hyperglycemia, inflammatory reactions and oxidative stress accelerate the apoptosis of cells in the retina resulting in the state of retinopathy. Both of these things explain why older people are more vulnerable to DR which eventually were found to increase with the increasing of age [3]. Research in China found that the average age of NPDR patients $60.75 \pm 8.74$ years and the average age of PDR patients were $58 \pm 5$ years [4]. Studies above did not differ much from the results of this study. Logistic regression multivariate analysis in this study found that age increased risk of $1.3 \%$ of the prevalence of PDR.

Gender is an important risk factor besides age in PDR and NPDR patients. Some studies show differences in sex characteristics in PDR and NPDR patients. Some studies in Spain reported the prevalence between men and women with NPDR was the same, that was 50\%. Another study found $55 \%$ of women, but a study in Portugal reported that $63.2 \%$ of the men in their study were in the NPDR group [5], [6], [7]. A study found that $51.11 \%$ of PDR patients were men. Research in Japan reported that PDR was found in 50\% of men and $50 \%$ of women [6]. However, there were several studies which show the opposite. A study showed that $54.4 \%$ of PDR patients were women [8]. The sex characteristics of the PDR and NPDR groups in this study are almost similar to some previous studies. Lifestyle and economic status like the habits of men who mostly smoke, consume coffee, alcohol, soft drinks, and minimal activity often increase the progression of diabetic retinopathy to PDR [8], [9]. Other factors that support the tendency of PDR patients are men, namely factors that men tend to ignore the early symptom so that patients often come to treatment when the symptoms get worse [2], [6], [10].

Duration of DM is one of the factors that associated with the increase of the occurrence of DR [11], [24]. Hyperglycemia exposure for a long time can increase biochemical and physiological changes, in the form of cellular changes in the basement retinal cell membrane resulting in the damage of the retinal capillary arteries, endothelial cell proliferation and thickening of the basement membrane resulting in capillary occlusion and nonperfusion of the retina. Capillary occlusion will cause bleeding and the emerge of the new fragile blood vessels so that it can cause recurrent bleeding which can reduce the sharpness of the vision [13]. Several studies have shown some variations in the duration of suffering from DM until later they found the NPDR and PDR complications. The incidence of diabetic retinopathy after four years of follow-up was around $50 \%$ in type 1 and type $2 \mathrm{DM}$, and after ten years of follow-up it became 74\% [14]. The study in India found that the duration of DM was the strongest predictor on the development and progression of retinopathy diabetic $(p=0.001)$ [15]. The results of this study were almost similar to studies that have been done before, the multivariate analysis showed that the duration of diagnosis of DM increased the risk by $0.59 \%$ of the prevalence of PDR.

HbA1c levels indicate the amount of glycated hemoglobin due to the long-term serum glucose exposure. High levels of HbAlc indicate an uncontrolled condition of hyperglycemia for the past 3 months [7]. The effect of this blood sugar control is related to the complications of DM that occur. Good HbAlc control $(<7 \%)$ can reduce the progressivity of the complication that occur [16].

Some studies show that DM control was said to be good if the $\mathrm{HbA} 1 \mathrm{c}$ number is $<6.5 \%$. A research shows that the cut-off point of diabetic retinopathy patients is $\geq 7.6 \%$ with AUC (area under the curve) $82 \%$ [10]. The study showed a 
cut-off point of diabetic retinopathy patients $\geq 7.3 \%$ [17]. Mitchell (2010)'s research showed that the cut-off point of diabetic retinopathy patients was $\geq 7.8 \%$ [12]. In this study, the prevalence ratio (RP) of PDR had been obtained at 3.87, with CI 95\% (1.96 - 7.67) with $\mathrm{p}<0.001$. The prevalence ratio $(\mathrm{RP})>1$ and $\mathrm{CI}$ was always above 1 , having the understanding that high $\mathrm{HbAlc}$ is a risk factor for PDR and high $\mathrm{HbAlc}$ increases the prevalence of PDR. These studies prove that poor $\mathrm{HbAlc}$ control will increase the incidence of microvascular complications in DM, one of which is diabetic retinopathy. In conclusion, $\mathrm{HbA} 1 \mathrm{c}$ increased the prevalence of PDR. The level of $\mathrm{HbAl}>7.7 \%$ increased the prevalence of PDR 3.87 times compared to the level of haemoglobin glycosylate $(\mathrm{HbA} 1 \mathrm{c})<7.7 \%$. Multivariate analysis showed a stronger relationship, where haemoglobin glycosylate levels (HbA1c) $>7.7 \%$ increased the prevalence of PDR 18.32 times in compared to haemoglobin glycosylate (HbAlc) levels $<7.7 \%$.

Further research is needed to evaluate the further consequences of high HbA1c levels. This study is a crosssectional study where the data collection was done at one point in time, so we cannot determine the lasting influence of high $\mathrm{HbA1c}$ levels on the progression of DR in patients with $\mathrm{DM}$ and poor glycemic control.

\section{REFERENCES}

[1] Zheng Y, Congdon N, Hess N, Chan M. The Worldwide Epidemic of Retinopathy Diabetic. Indian Journal of Ophthalmology. 2012. 60: 428-31.

DOI: 10.4103/0301-4738.100542 PMid: 22944754 PMCid: PMC3491270

[2] Sulaiman, Suhaiza, Mkthar AN, Ismail, Jeriah. Glicemic Control Among Type II Diabetics Patients in Kelatan. NCD Malaysia. 2010. 3(3): 1-5.

[3] Kowluru RA, Menon B, Gierhart. Beneficial Effect of Zeaxanthin on Retinal Metabolic Abnormalities in Diabetic Rats. Investigative Ophthalmology and Visual Science. 2008. 49 (4):1645-50. https://doi.org/10.1167/iovs.07-0764 PMID: 18385086.

[4] Xu J, Du KF, Chen XC, Zhou JQ. Diabetic Retinopathy in Diabetes Mellitus Patient. Journal of Ophthalmology. 2013. 20: 24-8.

[5] Stratton IM, Adler AI, Neil HAW, Matthews DR, Manley A. Intensive Blood Glucose Control with Sulphonylureas or Insulin Compared with Conventional Treatment and Risk of Complications in Patients with Type 2 Diabetes. Lans Diabetes Journal. 2012. 352: $837-53$.

[6] Funatsu H, Yamashita H, Ikeda T, Mimura T, Eguchi S, Hori S. Vitreous And Retina Related to Diabetic Retinopathy. American Academy of Ophtalmology. 2011. 110: 1690-6.

[7] Maa AY and Sullivan BR. Relationship of Hemoglobin A1c with the Presence and Severity of Retinopathy Upon Initial Screening of type II Diabetes Mellitus. American Journal of Ophthalmology. 2007. 114: 456-457. https://doi.org/10.1016/j.ajo.2007.04.008.

[8] Hartnett ME, Stratton RD, Browne RW, Rosner BA, Lanham RJ, Armstrong D. Severity of Diabetic Retinopathy. Diabetes Care. 2010. 23: 234-40.

[9] Javadi MA, Katibeh M, Rafati N, Dehghan MH, Zayeri F, Yaseri M. Prevalence of Diabetic Retinopathy in Tehran Province: A Population-Based Study. BMC Ophtalmology. 2010. 9 (12): 1-8.

[10] Dirani M, Xie J, Fenwick E, Benarous R, Rees G, Wong TY. Are Obesity and Anthopometry Risk Factors for Retinopati diabetik? : The Diabetes Management Project. Investigative Ophthalmology \& Visual Science Journal. 2011. 52: 4416-4421.

[11] Bin H, Li W, Yuan-Juan G, Jun-Feng H, Ming L. Factors Associated with Diabetic Retinopathy in Patients with Type 2 Diabetes Mellitus. International Journal of Endocrinology. 2012. 1-8

[12] Mitchell P and Foran S. Guidelines Management of Retinopathy diabetic. First Edition. Australia: Commonwealth Press. 2009. 17-18.

[13] Cruickshanks KJ and Moss SE. Relationship of Hyperglycemia to the Long Term Incidence and Progression of Retinopathy Diabetik. Arch Intern Med Journal. 2011. 154: 2169-2178.
[14] Doft BH, Kingsley LA, Orchard TJ, Kuller L, Drash A, Becker D The Association between Long Term Diabetic Control and Early Retinopathy. Ophthalmology Journal. 2010. 91: 763-769.

[15] Cull CA, Hadden D, Turner RC, and Holman RR. The Effect of Intensive Treatment of Diabetes on the Development and Progression of Long Term Complications in Insulin Dependent Diabetes Mellitus. New England Journal Med. 2009. 329: 977-986.

[16] Gupta V, Gupta A, Dogra MR, Singh R. Retinopathy diabetic: Atlas and Text. First Edition. New Delhi: Jaypee Brothers. 2009. 23-50.

[17] Khandekar R, Lawatii JA, Mohammed AJ, Raisi L. Retinopathy Diabetic in Oman: A Hospital Based Study. British Medical Journal. 2011. 87: 1061-1064. 